\title{
Induction of Glutathione S-transferase Activity in Triatoma infestans
}

\author{
JL Sívori, N Casabé, EN Zerba, EJ Wood*/+
Centro de Investigaciones de Plagas e Insecticidas-CIPEIN-(CITEFA-CONICET), J Zufriategui 4380, Villa Martelli (1603), Buenos Aires, Argentina *Facultad de Ciencias Exactas y Naturales,
Universidad de Buenos Aires, Argentina

\begin{abstract}
Several synthetic pesticides and allelochemicals used to treat Triatoma infestans adults by topic application showed some degree of cytosolic glutathione S-transferase (GST) induction. General inducers of detoxication systems such as phenobarbital and 3-methylcholantrene topically applied on T. infestans resulted in no GST induction. Meanwhile, general insecticide synergist such as piperonyl butoxide (160 $\mu \mathrm{g} /$ insect) increased the GST-activity in the range of 120-140\%.

Insects injected with reduced glutathione (300 $\mathrm{mg} / \mathrm{insect}$ ) presented at the forth day elevated GST activity.
\end{abstract}

Key words: Triatoma infestans - glutathione S-transferase - induction

Insects can metabolize and thereby degrade toxic or otherwise detrimental chemicals for surviving in a chemically unfriendly environment. While all insects probably possess detoxicative capacity, the amount can be expected to vary among species, with developmental stage, and with the nature of insect's recent environment. Variation in this activity is responsible, at least in part, for the selective toxicity of insecticides, the development of resistance to insecticides, and the selection of host plants. Detoxication in insects studies have revealed that further versatility in the adaptation of insects to environment is provided by the phenomenon of induction.

This is the process in which a chemical stimulus enhances the activity of the detoxication system by the production of additional enzymes. The induction of detoxication systems is not limited to insects, actually, the insects's detoxication systems are similar to those of more evolved animals. Furthermore, many chemicals that induce these enzymes in mammals are also active in insects.

Evidence shows that the enzymes involved in detoxication activity are adaptive in nature, i.e., they are regulated.

This investigation received financial support from UNDP/World Bank WHO Special Programme for Research and Trainning in Tropical Diseases, and from the Consejo Nacional de Investigaciones Científicas y Técnicas de la Argentina.

${ }^{+}$Corresponding author. Fax: +54-1-7095334

Received 10 April 1997

Accepted 7 July 1997
Probably the first reports of induction in insects were those of Agosin and Dinamarca (1963) who observed the phenomenon in Triatoma infestans, a blood-sucking insect, when this species was treated with DDT [1,1,1-trichloro-2,2-bis(4chlorophenyl)ethane]. They found that DDT increased the level of nicotinamide adenine dinucleotide phosphate (NADP), which is an important cofactor in microsomal oxidation. Later, they showed that the increased level of NADP following DDT treatment resulted from increased activity of NAD-kinase. In 1969, Agosin et al. demonstrated that DDT metabolism was indeed more rapid in treated insects.

These workers suggested that, since DDT is metabolized in some species by microsomal oxidases its induction might be related to DDT resistance.

It is clear from years of study of resistance to insecticides in various species of insects that the most important factor in the insect's defensive system is an increased capacity to detoxify the insecticide, most likely as a result of the production of additional enzymes of detoxication (Syvanen et al. 1996).

Glutathione S-transferases (GST) are one of the most general and efficient xenobiotic detoxication systems in all animals (O’Brien \& Tew 1996, Sivori et al. 1997). In insects GST have been induced and is becoming recognized for their importance in the metabolic detoxication of insecticides (Yu 1996), of allelochemicals from host plants (Yu 1993, Wadleigh 1988), in protecting insects from the toxic effects of active oxygen species (Ahmad \& Pardini 1990, Parkes et al. 1993, Zaman et al. 1994, Hodnick et al. 1996) and for the practical 
role of GST induction in turning on the detoxifying enzymes enhancing the defense machinery, speeding the development of resistance and causing cross-tolerance to other pesticides (Anspauch et al. 1994, Hinkle et al. 1995, Carlini et al. 1995).

Searching selective insecticide synergists for chemical control of Triatominae, we have studied the distribution and properties of GST from $T$. infestans (Wood et al. 1986a) and have found natural products of flavonoid type such as gossypol and quercetin and some triphenylmethane dyes (Thymol blue) capable of inhibiting in vitro T. infestans GST (Wood et al. 1990). Currently we have studied the mechanism of synergism of fenitrothion due to GST inhibitors in T. infestans (Sivori 1993).

In the present paper, we attempted an initial study on T. infestans GST induction because of its importance in the chemical control national campaigns of the main vector of the major endemic disease in Argentina (Chagas disease).

To the best of our knowledge this is the first study to demonstrate that GST induction is feasible in Hemiptera (Reduviidae) specially in vectors of Chagas disease.

\section{MATERIALS AND METHODS}

Chemicals - 1-chloro-2,4-dinitrobenzene (CDNB) was obtained from Janssen Chemical, Beerse, Belgium. All other reagents were purchased from Sigma Chemical Co., USA.

Insecticides - DDT was from a Pesticide Standard Kit (Analabs, USA). 2,4-D (2,4-dichlorophenoxyacetic acid) was a gift from Companía Química (Argentina). Malathion [S-1,2-bis (ethoxycarbony)ethyl O,O-dimethyl phosphorothioate] was from Cyanamid (Argentina). Dioxabenzofos(2-methoxy-4H-1,3,2-benzodioxaphosphinine-2-sulfide), fenitrothion (O,O-dimethyl O-4-nitro-m-tolyl phosphorothioate) and tetramethrin (3,4,5,6-tetrahydrophthalimidomethyl-cis,trans-chrysantemate) were gifts from Sumitomo (Japan).

Biological material - T. infestans were obtained from a colony maintained in our laboratory at $30^{\circ} \mathrm{C}$ and $50-60 \% \mathrm{RH}$ over a period of 25 years (Wood et al. 1975). The experimental work was done on T. infestans males, 12-14 days old (160$180 \mathrm{mg}$ body weight), fasted for two weeks.

Enzyme preparation - Adult T. infestans fasted for 15 days, without digestive system and head, were homogenized in distilled water, centrifuged at $10,000 \mathrm{x} \mathrm{g}$ for $30 \mathrm{~min}$. The obtained supernatant was the source for GST activity.

Protein concentration - Protein concentrations in the homogenates were determined by the method of Lowry et al. (1951). Bovine serum albumin was used as a standard.
Determination of enzyme activity - GST activity was assayed using the procedure described by Habig et al. (1974) using CDNB as substrate, in ultraviolet (UV) semi microcuvettes $(4 \mathrm{ml})$ (Fisher Scientific) by sequential addition of $0.1 \mathrm{M}$ phosphate buffer $\mathrm{pH} 6.5(1.78 \mathrm{ml})$, enzyme preparation as above $(0.1 \mathrm{ml}), 50 \mathrm{mM}$ of reduced GSH solution in buffer $(0.1 \mathrm{ml})$ and $50 \mathrm{mM} \mathrm{CDNB}$ solution in acetonitrile $(0.02 \mathrm{ml})(2 \mathrm{ml}$ final volume of the routine incubation mixture). Enzyme activity was determined by continuously monitoring the change in absorbance at $340 \mathrm{~nm}$ for $3 \mathrm{~min}$ at $25^{\circ} \mathrm{C}$ with a Shimadzu UV-160 spectrophotometer .

Treatment with GST-inducer candidates - T. infestans males (160-180 mg) were topically treated with acetonic solutions of different chemicals and kept individually in separate vials for 24 $\mathrm{hr}$ at $30^{\circ} \mathrm{C}$ and $50-60 \% \mathrm{RH}$. Homogenates (as described) were performed in pools of 5 insects and every enzyme activity determination was the average of 3 independent pools of 5 insects.

\section{RESULTS}

Table I shows that some synthetic pesticides had induction effect on GST activity from $T$. infestans adults. The organochlorinated insecticide DDT and the phenoxyacetic herbicide $2,4-\mathrm{D}$ presented only a moderate enhancing effect of GST activity. The organophosphorus (OP) insecticide dioxabenzofos (Salithion) and the pyrethroid tetramethrin instead showed a significant increase in GST activity in terms of specific enzyme activity. Fenitrothion and malathion (OP-insecticides) yielded an intermediate inductive effect.

The effect of allelochemicals on T. infestans

\section{TABLE I}

Effect of pesticides on Triatoma infestans cytosolic glutathione S-transferase activity

\begin{tabular}{|c|c|c|c|}
\hline Treatment & $\begin{array}{c}\text { Dose } \\
(\mu \mathrm{g} / \text { insect })\end{array}$ & $\begin{array}{c}\text { GST activity } \\
\left(\mu \mathrm{mol} \mathrm{min}^{-1} \mathrm{mg}^{-1}\right)\end{array}$ & $\%$ of control \\
\hline Control & 0 & $32 \pm 3$ & 100 \\
\hline DDT & 150 & $39 \pm 3$ & 122 \\
\hline Fenitrothion & 0.5 & $47 \pm 3$ & $146^{b}$ \\
\hline Malathion & 0.5 & $44 \pm 4$ & $138^{b}$ \\
\hline Salithion & $0.125^{a}$ & $56 \pm 4$ & $173^{b}$ \\
\hline Tetramethrin & 0.35 & $60 \pm 4$ & $187^{b}$ \\
\hline $2,4 \mathrm{D}$ & 160 & $36 \pm 2$ & 114 \\
\hline
\end{tabular}

Data represent average of 3 independent pools of 5 insects each. Values are expressed as mean \pm standard deviation. GST: glutathione S-transferase; DDT: 1,1,1trichloro-2,2-di(chlorophenyl)ethane; 2,4 D: 2,4dichlorophenoxy acetic acid; $a$ : 2 consecutive topic applications (24 hr apart); $b: \mathrm{p}<0.05$ ( $t$ test). 
cytosolic GST activity is shown in Table II. Flavone, the parent substance of all flavonoids, caused almost no increase in $T$. infestans GST activity. Quercetin and gossypol are related compounds, both are natural products from the flavonoid group, that showed to be active in diminishing the GST activity of $T$. infestans. The plant substances indole-3-carbinol (I-3-C) and indole-3-acetonitrile (I3-A) increased the GST activity being the former one the most active as an inducer.

When general inducers of detoxication systems were assayed, such as phenobarbitone or 3methylcholantrene, resulted in no GST induction in T. infestans (Table III).

On the other hand, the general insecticide syn-

\section{TABLE II}

Effects of allelochemicals on Triatoma infestans cytosolic glutathione S-transferase activity

\begin{tabular}{|c|c|c|c|}
\hline Treatment & $\begin{array}{c}\text { Dose } \\
(\mu \mathrm{g} / \text { insect })\end{array}$ & 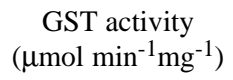 & $\%$ of control \\
\hline Control & 0 & $32 \pm 3$ & 100 \\
\hline $\begin{array}{l}\text { Indole-3- } \\
\text { carbinol } \\
\text { ( I-3-C) }\end{array}$ & 20 & $46 \pm 3$ & $142^{a}$ \\
\hline $\begin{array}{l}\text { Indole-3- } \\
\text { aceto-nitrilo } \\
\text { (I-3-A) }\end{array}$ & 20 & $37 \pm 2$ & 116 \\
\hline Flavone & 20 & $35 \pm 2$ & 109 \\
\hline Quercetin & 20 & $15 \pm 3$ & $47^{a}$ \\
\hline Gossypol & 20 & $25 \pm 3$ & $78^{a}$ \\
\hline
\end{tabular}

Data represent average of 3 independent pools of 5 insects each. Values are expressed as mean \pm standard deviation. GST: glutathione S-transferase; $a$ : $\mathrm{p}<0.05(t$ test).

TABLE III

Effects of laboratory inducers and synergists on Triatoma infestans cytosolic glutathione S-transferase activity

\begin{tabular}{lccc}
\hline Treatment & $\begin{array}{c}\text { Dose } \\
(\mu \mathrm{g} / \text { insect })\end{array}$ & $\begin{array}{c}\text { GST activity } \\
\left(\mu \mathrm{mol} \mathrm{min}^{-1} \mathrm{mg}^{-1}\right)\end{array}$ & $\%$ of control \\
\hline $\begin{array}{l}\text { Control } \\
\text { Phenobarbitone }\end{array}$ & 350 & $32 \pm 3$ & 100 \\
$\begin{array}{l}3 \text {-methyl- } \\
\text { cholantrene }\end{array}$ & 350 & $36 \pm 3$ & 112 \\
$\begin{array}{l}\text { Piperonyl } \\
\text { butoxide }\end{array}$ & 160 & $40 \pm 2$ & 109 \\
\hline
\end{tabular}

Data represent average of 3 independent pools of 5 insects each. Values are expressed as mean \pm standard deviation. GST: glutathione S-transferase; $a$ : $\mathrm{p}<0.05(t$ test). ergist piperonyl butoxide topically applied $(160 \mu \mathrm{g} /$ insect) on T. infestans males produced $24 \mathrm{hr}$ later an increase in GST activity in the range of $120 \%$ $140 \%$ on the control of untreated insects (Table III).

Exposure to solvents such as ethanol or phorone showed no induction, furthermore a mild but a significative GST inhibition (40\%) was obtained when $0.89 \mu \mathrm{g}$ phorone/insect was topically applied on $T$. infestans adults (Table IV).

Injected adults with $3 \mu \mathrm{l}$ of a $10 \%$ glutathione (GSH) solution in water showed after 4 days an increase in GST activity of $300 \%$ comparing to control (Table IV).

\section{TABLE IV}

Effect of solvents and reduced glutathione on Triatoma infestans cytosolic glutathione S-transferase activity

\begin{tabular}{|c|c|c|c|}
\hline Treatment & $\begin{array}{c}\text { Dose } \\
(\mu \mathrm{g} / \text { insect })\end{array}$ & 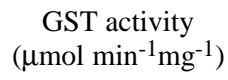 & $\%$ of control \\
\hline Control & 0 & $32 \pm 3$ & 100 \\
\hline Ethanol & 0.89 & $33 \pm 2$ & 100 \\
\hline Phorone & 0.89 & $19 \pm 3$ & $60^{c}$ \\
\hline $\begin{array}{l}\text { Reduced } \\
\text { glutathione } \\
\text { (GSH) }\end{array}$ & $300^{a}$ & $92 \pm 5^{b}$ & $287^{c}$ \\
\hline
\end{tabular}

Data represent average of 3 independent pools of 5 insects each. Values are expressed as mean \pm standard deviation. GST: glutathione S-transferase; $a$ : i.c. (intracellomatic) injection of $3 \mu \mathrm{l}$ of a $10 \% \mathrm{GSH}$ solution $b$ : determined 4 days later; $\mathrm{c}$ : $\mathrm{p}<0.05$ ( $t$ test).

\section{DISCUSSION}

GST (E.C.2.5.1.18) are a group of multifunctional proteins serving several roles in detoxication. Distribution of GSTs is known to be widespread in nature and there is no question about the importance of these enzyme systems for they are essential in explaining selective toxicity and resistance mechanism among various organisms. The detoxication function of these enzymes may achieve a particular significance in the insect world by contributing to the development of resistance to insecticides by catalyzing their degradation (Yu 1996). In an earlier publication (Wood et al. 1986b) the hemolymph from $T$. infestans was shown to be capable of rendering aqueous metabolites of parathion when incubated in the presence of reduced GSH. Then, the citosolic GST from T. infestans showed to play an important role in metabolizing 14C-organophosphorus insecticides (Wood et al. 1986a). In the way of studying the regulation of 
this key metabolic system we have started studying the inhibition of the T. infestans GST activity (Wood et al. 1990, Sívori et al. 1997) and finally in the present work we are focussed in describing the action of several inducers of the GST activity in T. infestans.

The relevance of potential induction of biochemical defenses, specially GST, in $T$. infestans is a matter of economy and public health.

DDT exposure have been demonstrated to enhance mixed function oxidases (MFO) in $T$. infestans in the 60's by Agosin and Dinamarca (1963) and Agosin et al. (1969). DDT was also found to be most active in causing GST activity induction (150\%) in Musca domestica (Hayaoka \& Dauterman 1982). In T. infestans we found that DDT topical application produced a mild increase in GST activity (122\%) that may be responsible for certain insecticide tolerance.

OP insecticides have been used in Argentinian National Campaigns for vector control of Chagas disease during the 70's and mid 80's. These insecticides are known to be metabolized by GST, furthermore cases of insecticide resistance due to enhanced GST activity have been reported (Oppenoorth et al. 1979, Carlini et al. 1995, Syvanen et al. 1996). We were able to demonstrate in T. infestans that a single dose of topically applied malathion produced $138 \%$ increase in GST activity. Additionally, salithion in two consecutive topication (24 hr apart) yielded an increase of $173 \%$ of GST activity. Yadwad (1988) studied the fenitrothion effect in the castor semilooper Achae janata (Lepidoptera, Noctuidae). GST activity was determined in A. janata during larval, pupal and adult stages following treatment with sublethal and lethal doses of fenitrothion. Both doses of insecticide produced significant induction of enzyme activity. The rate of induction was not significantly different between insects that received sublethal and lethal doses of insecticides. Larvae treated with sodium barbitone along with fenitrothion, delayed the knockdown effect of the insecticide attributable to the increased induction of GST activity. In T. infestans a fenitrothion non-lethal dose produced $146 \%$ augmentation of GST activity.

Tetramethrin is one of the least active pyretroids in T. infestans (LD50 > 500 $\mu \mathrm{g} / \mathrm{g}$ ), meanwhile deltamethrin toxicity is $\mathrm{LD} 50=0.3 \mu \mathrm{g} / \mathrm{g}$ (Casabé et al. 1988); when adults were topicated with sublethal dose showed a significant increase of GST activity $(187 \%)$.

The 2,4-D herbicide showed an inhibitory action $\left(\mathrm{I}_{50}<5 \mu \mathrm{M}\right)$ in GST from human and rat erythrocytes (Vessey \& Boyer 1984, Singh \& Awasthi 1985). However, in T. infestans, topical application of 2,4-D produced a mild enhancement of GST activity (114\%).

Studies on phytophagous insects showed that diet may have a major effect on the synthesis of GST. GSTs have been induced by numerous xenobiotics, among them the naturally ocurring chemicals from host plants (Umbellifers and Crucifers) and allelochemicals (furanocoumarins, indoles and flavonoids) are the most potent inducers of the enzymes. GSTs have also been implicated in the resistance to insecticides and allelochemicals in insects. The high GST activity found in insecticide resistance in insects was associated with increased level of specific mRNA (Yu 1996). The microsomal epoxidase and GST in Lepidoptera (Diamondblack moth larvae) were induced by cruciferous host plants such as cabbage and their allelochemicals (Yu 1993). Furthermore, three Lepidoptera species were able to metabolize benzylthiocyanate (allelochemical) using larvae midgut soluble fraction as the enzyme source of GST and this enzyme activity was inducible by dietary indole 3-carbinol (I-3-C) (found in cruciferous vegetables), indole-3-acetonitrile (I-3-A), flavone and xanthotoxin (Wadleigh 1988). However, topical single application of I-3-A or flavone did not produce any significant increase in GST activity of $T$. infestans. On the other hand, I-3-C was the major inducer among the naturally ocurring candidates assayed in T. infestans (142\%). Natural compounds from the flavonoid group such as quercetin or gossypol in non-lethal topical applications showed GST activity inhibition rather than induction (Wood et al 1990).

Quercetin, myricetin, quercetagetin and delphinidin are flavonoids that act in insects mitochondrial respiration and can generate reactive oxygen species (ROS) during autooxidation or cyanide-induced oxygen consumption in vitro. Resistant species towards the acute toxicity of quercetin paralleled the endogenous activities of antioxidants enzymes (Hodnick et al. 1996). The antioxidant enzymatic defence of insects consist of superoxide dismutase (SOD), catalase (CAT), glutathione reductase (GR), GST and its peroxidase activity (GSTpx). Unlike mammalian species, insects possess very low levels of a glutathione peroxidase (GPOX)-like activity toward $\mathrm{H}_{2} \mathrm{O}_{2}$ (selenium-dependent GPOX found in mammals). However, the activity of selenium-independent GSTpox is unusually high in insects, suggesting that it plays a prominent role in scavenging deleterious lipid peroxides (LOOHs) (Ahmad \& Pardini 1990). Mercury also induces oxidative stress in insects as it does in vertebrates and provoques induction of antioxidant enzyme levels: GSTpox, SOD, GR, CAT in M. domestica and in Trichoplusia ni. (Zaman et al. 1994). 
Laboratory studies have been carried out with a number of inducers unlikely to be encountered in the field. T. infestans GST-activity was unresponsive to phenobarbital administration either topically applied or orally administered using an artificial feeder for hematophagous insects. Drosophila melanogaster GST activity has been reported also to be unresponsive to phenobarbital administration (Cochrane \& Leblanc 1986). Recently, Borgeraas et al. (1996) reported in the earthworm genus Eisenia that exposure of species $E$. andrei and E. veneta to trans-stilbene oxide, 3methylcholantrene and phenobarbital for three weeks did not elevate the activity of GST measured with CDNB and ethacrynic acid (ETHA) as substrates.

On the other hand, in $M$. domestica phenobarbital has been found to be an effective inducer of GST activity (Ottea \& Plapp 1981) and Lucilia cuprina responds to phenobarbital with a 3-4 times induction of activity with respect to CDNB and 3,4-dichloronitrobenzene (DCNB) (Kotze \& Rose 1987).

T. infestans GST-activity was also unresponsive to 3-methylcholantrene administration in contrast to several strains of Tribolium castaneum GST-activity that were strongly stimulated by phenobarbital, 3-methylcholantrene, and trans-stilbene oxide (Cohen 1986) and the microsomal GST in Aspergillus ochraceus TS that were effectively induced by 3-methyl cholantrene (Datta et al. 1994).

Piperonyl butoxide (PBO) is a widely used insecticide synergist of the methylenedioxyphenyl group. Its typical mechanism of action has been the inhibition of oxidative metabolism of insecticides due to cyt P-450 but it might be not the sole role of PBO (Farnham 1996). Studies showed that PBO at concentrations of $10 \mu \mathrm{M}$ or greater was an effective inhibitor of pyrethroid resistance esterases. Preliminary experiments with Aphis gossypii suggested $\mathrm{PBO}$ was capable of inhibiting esterase activity in this insect (Devonshire 1996). In addition, it has been suggested that PBO may be an active insecticide against cotton whitefly (Bemisia tabaci) (Devine 1996) and also effective in grain protection as an alternative chemical control (Adams 1996).

When T. infestans were topicated with non-lethal dose of piperonyl butoxide the GST-activity was moderately but significantly enhanced with respect to controls.

The practical role of this finding require elucidation by further experimentation as the interest in this traditional component of pyrethroid formulations is renewed on worldwide basis.

Ethanol treated T. infestans were unresponsive regarding the GST-activity, but the exposure to phorone (industrial solvent known to deplete GSH content) produced a significant inhibition of GSTactivity of $T$. infestans instead.

In contrast, when adult males were injected intracelomatically with massive but still non-lethal dose of GSH in the fourth day after injection the insects showed a maximum increase of GST-activity. This fact suggests that reduced glutathione in a massive dose could trigger the synthesis of the enzyme (GST).

These experiments constitute the grounds of future studies on GST-activity regulation in Chagas disease vectors for the potential relevance that this detoxication pathway may have in the results of chemical control actions.

Although relatively little attention has been paid to the effects of non-lethal doses of insecticides on GST regulation in $T$. infestans we have proposed to evaluate the GST activity of survivors in field trials. The insecticide treatments aftermath should be necessary to survey in future efficient chemical control campaigns.

\section{REFERENCES}

Adams M 1996. A satellite Symposium on Piperonyl Butoxide: a biologically active chemical with many diverse uses in insect control, p. 3. XX International Congress of Entomology, Florence, Italy .

Agosin M, Dinamarca ML 1963. The effect of DDT on the level of di- and triphosphopyridine nucleotides in Triatoma infestans. Exp Parasitol 13: 199-203.

Agosin M, Scaramelli N, Gil L, Letelier ME 1969. Some properties of the microsomal system metabolizing DDT in Triatoma infestans. Comp Biochem Physiol 29: 785-793.

Ahmad S, Pardini RS 1990. Mechanisms for regulating oxygen toxicity in phytofagous insects. Free Rad Biol Med 8: 401-413.

Anspauch DD, Rose RL, Koehler PG, Hodgson E, Roe RM 1994. Multiple mechanisms of pyrethroid resistance in the German cockroach, Blatella germanica (L.). Pestic Biochem Physiol 50: 138148.

Borgeraas JN, Nislen K, Stenersen J 1996. Methods of purification of glutathion transferases in the earthworm genus Eisenia and their characterization. Comp Biochem Physiol 114C: 129-140.

Carlini EJ, McPheron BA, Felland CM, Hull LA 1995. Biochemical mechanisms of azinphosmethyl resistance in the tufted apple bud moth Platynota idaeusalis. Pestic Biochem Physiol 51: 38-47.

Casabé N, Melgar F, Wood EJ, Zerba EN 1988. Insecticidal activity of pyrethroids against Triatoma infestans. Insect Sci Applic 9: 233-236.

Cochrane BJ, Leblanc GA 1986. Genetics of xenobiotic metabolism in Drosophila : Genetic and environmental factors affecting Glutathione S-transferase in larvae. Biochem Pharmacol 35: 1679-1684.

Cohen E 1986. Glutathione S-transferase activity and its induction in several strains of Tribolium 
castaneum. Entomol Exp App 41: 39-44.

Datta J, Dutta TK, Samanta TB 1994. Microsomal glutathione S-transferase (GST) isozymes in Aspergillus ochraceus TS: induction by 3-methyl cholanthrene. Biochem Biophys Research Comm 203: 1508-1514.

Devine G 1996. A satellite Symposium on Piperonyl Butoxide: a biologically active chemical with many diverse uses in insect control, p. 3. XX International Congress of Entomology, Florence, Italy.

Devonshire A 1996. A satellite Symposium on Piperonyl Butoxide: a biologically active chemical with many diverse uses in insect control, p. 3. XX International Congress of Entomology, Florence, Italy.

Farnham AW 1996. A satellite Symposium on Piperonyl Butoxide: a biologically active chemical with many diverse uses in insect control, p. 2. XX International Congress of Entomology, Florence, Italy.

Habig WH, Pabst MJ, Jacoby WB 1974. GlutathioneS-Transferase. The first enzymatic step in mercapturic acid formation. J Biol Chem 249: 7130-7139.

Hayaoka T, Dauterman WC 1982. Induction of glutathione S-transferase by Phenobarbital and pesticides in various housefly strains and its effects on toxicity. Pestic Biochem Physiol 17: 113-119.

Hinkle NC, Wadleigh RW, Koehler PG, Patterson RS 1995. Mechanisms of insecticide resistance in a strain of cat fleas (Siphonaptera:Pulicidae). J Entomol Sci 30: $43-48$.

Hodnick WF, Ahmad S, Pardini RS 1996. Induction of oxidative stress by redox active flavonoids, p.232. $212^{\text {th }}$ ACS National Meeting, Orlando, Florida.

Kotze AC, Rose HA 1987. Glutathione S-transferase in the Australian blowfly, Lucilia cuprina (Wiedemann). Pestic Biochem Physiol 29: 77-86.

Lowry OH, Rosebrough NJ, Farr AL, Randall RJ 1951. Protein measurement with the Folin phenol reagent. J Biol Chem 193: 265-275.

O'Brien ML, Tew KD 1996. Glutathione and related enzimes in multidrug resistance. Europ J Cancer 32A: 967-978.

Oppenoorth FJ, Van der Pas LJ, Houx NW 1979. Glutathione S-transferase and hydrolytic activity in a tetrachlorvinphos-resistant strain of housefly and their influence on resistance. Pestic Biochem Physiol 11: 176-178.

Ottea JA, Plapp FW Jr 1981. Induction of glutathione Stransferase by phenobarbital in the housefly. Pestic Biochem Physiol 15: 10-13.

Parkes TL, Hilliker AJ, Phillips JP 1993. Genetic and biochemical analysis of Glutathione-S-transferase in the oxygen defense system of Drosophila melanogaster. Genome 36: 1007-1014.

Singh SV, Awasthi YC 1985. Inhibition of human GST by 2,4-D and 2,4,5-T. Toxicol Appl Pharmacol 81 : 328-334.

Sívori JL 1993. Regulación de la glutatión S-transferasa de Triatoma infestans y su importancia en el proceso de intoxicación por insecticidas organofosforados. $\mathrm{Ph}$ D. Thesis. Universidad de Buenos Aires, Facultad de Ciencias Exactas y Naturales, 164 pp.

Sívori JL, Casabé NB, Wood EJ 1997. Glutathione Stransferases in non-vertebrates and mammals. Its role in detoxifying insecticides. Acta Bioq Clin Latinoamericana, in press.

Syvanen M, Zhou Z, Wharton J, Goldsbury C, Clark A 1996. Heterogeneity of the glutathione transferase genes encoding enzymes responsible for insecticide degradation in the housefly. J Mol Evol 43: 236240.

Vessey DA, Boyer TD 1984. Differential activation and inhibition of different forms of rat liver GST by the herbicides 2,4-D and 2,4,5, trichlorophenoxyacetate (2,4,5-T). Toxicol Appl Pharmacol 73: 492-498.

Wadleigh RW 1988. Metabolism of an organothiocyanate allelochemical by glutathione transferase in three lepidopterous insects. J Econ Entomol 81: 776-780.

Wood EJ, Melgar F, Zerba EN 1990. Inhibitors of the Glutathione S-transferases from Triatoma infestans. An Asoc Quím Argent 78 : 241-260.

Wood E, Casabé N, Melgar F, Zerba E 1986a. Distribution and properties of glutathione-S-transferase from Triatoma infestans. Comp Biochem Physiol 84B: 607-618.

Wood E J, Villar MIP, Melgar F, Zerba E 1986b. Mode of action of N-ethylmaleimide as parathion synergist in T. infestans. Pestic Biochem Physiol 26: 170182

Wood EJ, Zerba E, Picollo MI, Licastro S, Rúveda MA 1975. Algunas propiedades del sistema colinesterásico de la cabeza del Triatoma infestans (Klug). Acta Bioq Clin Latinoamericana 9: 159-163.

Yadwad VW 1988. Induction of glutathione S-transferase in the castor semilooper, Achaea janata (Lepidoptera, Noctuidae) following fenitrothion treatment. Biosciences 13: 139-146.

Yu SJ 1993. Induction of detoxification enzymes in phytophagous insects: Roles of insecticide synergists, larval age, and species. Arch Insect Biochem Physiol $24: 21-32$.

Yu SJ 1996 . Insect glutathione-S-transferase. Zool Stud 35: 9-19.

Zaman K, MacGill RS, Johnson JE, Amad S, Pardini RS 1994. An insect model for assessing mercury toxicity: effect of mercury on antioxidant enzyme activities of the housefly (Musca domestica) and the cabbage looper moth (Trichoplusia ni). Arch Environ Cont Toxicol 26: 114-118. 